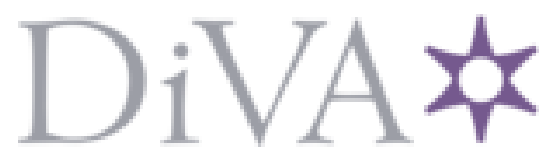

http://www.diva-portal.org

\title{
Postprint
}

This is the accepted version of a paper presented at HICSS-47, 47th Annual Hawaii International Conference on System Sciences 2014, Hilton Waikoloa, Big Island, Hawaii, USA, January 6-9, 2014.

Citation for the original published paper:

Akram, A., Bergquist, M., Åkesson, M. (2014)

Digital Visions vs. Product Practices: Understanding Tensions in Incumbent Manufacturing Firms.

In: Ralph H. Sprague, Jr. (ed.), Proceedings of the Annual Hawaii International Conference on System Sciences (pp. 4516-4525). Los Alamitos, CA: IEEE Computer Society https://doi.org/10.1109/HICSS.2014.562

N.B. When citing this work, cite the original published paper.

Permanent link to this version:

http://urn.kb.se/resolve?urn=urn:nbn:se:hh:diva-24137 


\section{Digital Visions vs. Product Practices: Understanding Tensions in Incumbent Manufacturing Firms}

\author{
Asif Akram \\ Halmstad University \\ asif.akram@hh.se
}

\author{
Magnus Bergquist \\ Halmstad University \\ University of Gothenburg \\ magnus.berquist@hh.se
}

\author{
Maria Åkesson \\ Halmstad University \\ maria.akesson@hh.se
}

\begin{abstract}
Incumbent manufacturing firms face challenges when expanding their product focus with digital services. Such expansion creates tensions in organizations in the servitization process. While management visions and conceptualizes new service oriented businesses, the actual practice of implementing these service concepts is influenced by the product paradigmatic way of thinking in the organization. This dominant thinking creates tensions between business visions and business practice. We use the case of remote diagnostics services to provide insights into a manufacturing firm's attempt to transform the dominant oriented business models into a new networked environment. We suggest that such acts that may or may not lead to transition are lingered by dominant logics related to the product focus. This indicates that firms are required to embed new logics into their existing practice in order to exploit the full potential of digital technology.
\end{abstract}

\section{Introduction}

The integration of digital technology in physical products challenges business development in incumbent manufacturing firms by expanding their business with services. This move can reformulate the relationship between product development and organizational processes and create tensions as companies go from product exploration to product exploitation [1]. Tensions in such environments are caused by the paradoxes emerging from combined product-service innovation complexity [2].

With the advancement of digital technologies, incumbent manufacturing firms show an increased trend to move from 'developing products' to 'developing solutions' or 'systems' [3]. This allows them to expand their business by providing services in addition to their core businesses. Broadly speaking, this movement of including services to manufacturing companies is known as servitization [4]. However, firms need to keep tight control in order to protect its revenue sources. This makes it difficult for them to keep pace with rapid technological advancements leading to counter effects instead of benefiting from the technology [5]. Previous studies on servitization have taken in account of either product or service based logic in changing economy while the uses of digital technologies play a key role and generate new kinds of tensions [4]. Recently, the IS research community is taking an interest in knowing what a 'digital technology implanted service' really means in relation to traditional notions of incumbent manufacturing firms (see e.g. [6, 7]. The literature suggests that the firms are required to focus on strategies, technologies, and organizational practices.

The phenomenon is particularly evident in the vehicle industry where incumbent manufacturing firms ${ }^{1}$ have visions to expand their business on the basis of embedded digital technology. The development of digital technology is established and operated by a heterogeneous collection of stakeholders, each governed by its own interests in the networked arrangement. Such a scenario sometimes also brings tension that can either stimulate or debilitate the process [8].

Organization literature has paid attention to the tensions between technological development and institutional practices (e.g. [9-11]). Recent IS literature, focusing on tensions between design paradigms and innovation of digital technology [12], argue that embedding digital components into a product represents challenge for incumbent firms due to the different digital innovation logic that is imposed into the cross-organizational design processes. Studying tensions in such a complex sociotechnical environment remain a focal research challenge and there is need for new theoretical lenses

\footnotetext{
${ }^{1}$ In this paper, incumbent manufacturing firms refer to firms producing vehicles such as buses, trucks etc.
} 
to understand the nature of these tensions [13]. However, embedding digital technology in products in many cases also encompasses a change from a product dominant to a service dominant logic [12, 14]. Such situations may give rise to tensions based on different motivations such as the urge to gain maximum economic benefit, the attitude towards inertia within incumbent firms, and establishment of new relationships with existing industry networks [11]. While these incumbent firms often do not fully understand the value of new technology and resist to new demanding logics, they are continuously facing tensions. Digital technologies thus play a key role in the transformation and serve as a primary source of innovation that introduces novel organizing logics, products and services [15]. Moreover, incumbent manufacturing firms incorporating digital services in the innovation process must handle the ambidexterity inherent in product-service complexity [2, 16, 17]. The expanded scope also brings changes to the business and innovation, and there is scarce understanding of tensions that bring these changes. Hence, the research question is

What are the tensions for incumbent manufacturing firms when innovating their business with digital services?

The paper contributes with (i) an understanding of tensions during digitalization; and (ii) a discussion on how these tensions can be understood from dominant logic perspective. Understanding these tensions can better inform firms about paradoxical situation that may arise during digital service innovation.

The paper proceeds as follows: First, we describe tensions in a digitalized environment. In this case, it is related to the exploration of services based on a remote diagnostics system. The following section gives a background to the research approach and methodology while contextualizing the empirical situation. Thereafter, empirical finding outlines the tensions from the systematic analysis of empirical material. Finally, the paper discusses the implications of tensions for incumbent firm in IS followed by conclusion and future work.

\section{Tensions in digitalized environment}

The complex and non-linear nature of new sociotechnical systems has led to growth in inquiry into tensions and related phenomena such as paradoxes. This has become more evident in the processes where digital technologies are applied to broader social and institutional context. As the environment in such situations becomes faster paced and competitive, and internal processes become more complex, tensions are more tangible and acute.
In general, studies on tensions started with a call by Cameron and Quinn [18] who ask to move beyond oversimplified either/or notion and better explore competing demands of innovation and change. Tensions have been described as the frictions that can inhibit or energize incumbent manufacturing firm's performance in a competing market [8]. Following studies have considered paradoxes with respect to culture [19], authority structures [20] and advocating for multiple orientation [21] from range of perspectives [11]. Tensions that arose include tensions between collaboration and control [22], flexibility and efficiency [23], exploration and exploitation [24], and change and control [13, 25].

Incumbent manufacturing firms expanding their business based on digital technology need to cater with their relationships with relevant stakeholders. This process makes the network more complex and cumbersome giving birth to many tensions in the digitalized environment. These tensions are multiple perspectives and lead to many unintended consequences which may or may not create paradoxical situations [13]. Examples of such changes can be, for example, service design, organizational strategy, and organizational transformation. Service design change arise from the thinking that design of digital services is significantly different from design of products. This difference leads to marginal risk that may out-weight the benefits of potential profit from the technology. Another change is associated with the servicesoriented strategy, which requires organizations to adopt necessary organizational structure and process with digitalization. This also requires a customeroriented strategy as well as an attitude to value digital services. Finally, another important area is related to organizational transformation that underpins the assumption that the culture associated with digitalization is different from traditional product culture [4, 26, 27]. However, such a change in incumbent firms requires a shift of corporate mindset to take on digital service logic. Moreover, it requires changes to long standing practices and attitudes. But during the change where the underlying logic is not understood more tensions are created and, this is referred to as the 'service paradox' [28, 29]. However, the studies on understanding the tensions are still thin and tensions in this context need to be explored further especially in networked environments brought by digital technologies.

An overview of tensions between vision and practice is shown in Figure 1 below: 


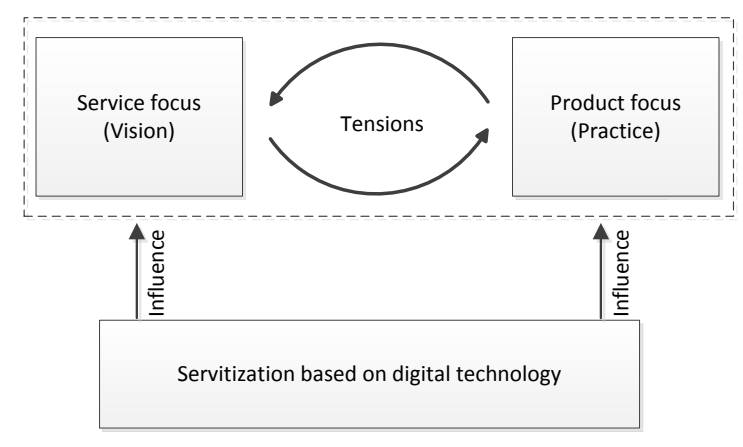

Figure 1. Tensions in incumbent firms in digitalized environment

\section{Dominant logic}

A dominant logic is defined as the worldview and mindset that is normative for senior managers in an organization [30]. Information is filtered through the dominant logic and conceptualizes business and the strategic tools used to make decisions and accomplish goals in an organization. The dominant logic is enacted in organizational practices in a way that it reinforces the logic as "the right way" of doing things in relation to the prevailing cognitive schemas. Dominant logics are associated with managers' problem-solving and strategic behavior. The source for dominant logic is previous economic success. Managers effectively pursuing business and organizational success will therefore positively reinforce the behaviors that led to success. The repertoire of mindsets and practices that are developed will be based on the schema encompassing the logic.

Later works on dominant logic concept also discuss it as an emergent property of complex adaptive organizations. Such developments include a retrospective account on how the concept was developed [31]. Although initial developments focused on diversification in organizations, later works reflect environmental-driven organizational change. Such kinds of changes are argued around the phenomenon why organizations see change in environment but unable to act.

With digitalization, environment in incumbent manufacturing firms change with the requirement of a new logic. This, in many cases, also blurs organizational boundaries. On one hand, it shatters the dominant service model and stability of the firm[13], while on the other hand it requires a new logic which is different from the traditional product logic [15].

\section{Methodology}

\subsection{Research setting and design}

The question of how digitalization tensions are created in incumbent manufacturing firms was studied within a project in the vehicle industry. We conducted a 3 year collaborative study [32] at one of the world's largest vehicle manufacturer, GlobalAlpha. The study is a part of a research project initiated by GlobalAlpha and aims to implement a state of the art remote diagnostics technology. This digital technology involves monitoring the status of vehicles on roads from remote location and is capable of providing information about faults or errors before a breakdown occur. To exploit the benefits from the digital technology, GlobalAlpha came with the vision to provide predictive maintenance and repair services.

GlobalAlpha was established in 1920s to manufacture vehicles of high quality for extreme conditions. It has more than 100000 employees with production facilities in 19 countries and is selling products globally. Over decades the company has expanded its manufacturing business into a number of areas such as: buses, trucks, construction equipment, automobile, marine and industrial engines, and components for the aerospace industry. During its journey of developing a variety of high quality products, the company started providing services as add-on function to their products. Now it envisions providing high quality services in parallel to their traditional manufacturing business. A majority of its customers are companies within transportation or construction industries while keeping their productivity and profitability as key concerns of itself. The company also experiences a high level of competition in the industry by other competitors who manufacture similar kinds of vehicles and are involved in similar businesses.

There are number of reasons why we studied the vehicle manufacturing, GlobalAlpha, as the empirical setting for our study. First, GlobalAlpha provides an example of the established incumbent product manufacturing company. Second, in view of advancement of digital technology and the long history of vehicle industry, vehicle manufacturers can be sensitive to tensions during the transition towards service business. Third, the company operates in an industry characterized by a long period of incremental innovation. Fourth, GlobalAlpha is involved in activities related to the development of digital technology and digitalizing their products to create new opportunities with digital services. 
The development of new services was studied from the first visionary meetings to the actual development. The research project included management from GlobalAlpha as well as managers from its subsidiaries, Alpha 1, Alpha 2 and Alpha 3. The first phase of the study focused on how management envisioned new remote diagnostic technology and its potential. The second phase of the study followed the implementation studying different practices around the exploitation of technology's benefits in the new service context. We focused on capturing a comprehensive view of the vision. The project management at GlobalAlpha involved project manager, service development manager, service business manager and technology development manager. Management from the subsidiaries involved in the research project included the business area representatives, repair and maintenance manager and service planner. All managers were involved in forming strategies and making decisions in their respective areas.

\subsection{Data collection}

In order to collect data, the study conducted a number of various but related activities. The data collection phase ranged from April 2010 to May 2013 involving different kinds of activities. These activities included interviews, workshops, project meetings, service development meetings, observations, weekly project newsletters, and e-mail correspondences.

The project started with exploration phase by conducting service development meetings with the purpose to define the scope of the project. Each of the meetings lasted between 1-2 hours and served as the basis for many other activities. Around 30 service development meetings were conducted at regular interval of biweekly times and on demand. Meeting minutes and summary documents were produced at the end of each meeting. The initial findings depicted an increasing interest among the participants to identify the potential of the technology. The meetings also reflected on industry's concerns regarding the challenges while dealing with the technology.

The initial project meetings were followed by seven semi-structured interviews guided by the work of Myers and Newman [33], and Schultze and Avital [34] to get deeper understanding of the context and vision. Three interviews were conducted with business area representatives, one with a service planner and one with a maintenance manager. The purposes of these interviews were to get a rich picture of the complex environment, to capture the vision of the company and how they were conducting their businesses.

A further rich picture was obtained from three workshops that were conducted as half-day activities with business area representatives from GlobalAlpha subsidiaries, project manager and service development manager from Alpha 1. Value networks were mapped with the particular business area representatives to understand the business environment and to envision the potential of services developed by digital technology. Discussions were also made during the workshops based on the mapped networks. These discussions were recorded and later transcribed to input for richer picture of the vision.

In addition to interviews and workshops, fourteen monthly project meetings (each of which was three hours in length) were held. These were generic in nature and discussed project issues and opportunities that occurred across the disciplines, such as technical, service development and business. Cross-disciplinary inputs about technology's potentials and way of working were collected from project, service development, service business and technology managers.

Finally, all these activities were supplemented with fifty-four weekly project newsletters, e-mail correspondences, and other project and company documents. Table 1 summarizes the activities and participants.

Table 1. Summary of data collection activities

\begin{tabular}{|l|l|}
\hline Activities and sources & Participants \\
\hline 30 Service development meetings & 7 \\
\hline $\begin{array}{l}\text { 3 Workshops with business area } \\
\text { representatives from Alpha 1, } \\
\text { Alpha 2 and Alpha 3 }\end{array}$ & 5 \\
\hline 20 Monthly project meetings & $8-11$ \\
\hline $\begin{array}{l}3 \text { Semi-structured interview with } \\
\text { business are representatives from } \\
\text { Alpha 1, Alpha 2 and Alpha 3 }\end{array}$ & 2 \\
\hline $\begin{array}{l}1 \text { Semi-structured interview with } \\
\text { service development manager }\end{array}$ & 4 \\
\hline $\begin{array}{l}1 \text { Semi-structured interview with } \\
\text { technology development manager }\end{array}$ & 3 \\
\hline $\begin{array}{l}1 \text { Semi-structured interview with } \\
\text { project manager }\end{array}$ & 3 \\
\hline $\begin{array}{l}1 \text { Semi-structured interview with } \\
\text { repair and maintenance manager }\end{array}$ & 4 \\
\hline 54 Weekly project newsletters & 11 \\
\hline
\end{tabular}




\subsection{Data analysis}

After transcribing interviews the data analysis phase started and consisted of the following activities: we first reviewed each of the collected interview transcripts, notes from service development and monthly meetings, reports from workshop, field notes, weekly newsletter, and other company documents. The purpose of this review was to determine whether they provided information related to our goal of understanding tensions between vision and practice in GlobalAlpha. This process led us to relevant documents as mentioned in table 1 . We then subsumed the material in to larger categories of vision and practice related to a particular theme e.g. technology design and development, business model, collaboration with customers and so on. Later, we organized the data according to vision, practices and tensions associated with each theme. This lead our way to identify tensions that emerged as the result of contradictory practices of the firm in relation to its vision.

Our general data analysis was led by the suggestion by Miles and Huberman [32] from the collected material. Reflecting on logic of the hermeneutic circle, the data analysis was based on iteration between two analytical foci: 'the interdependent meaning of parts and the whole they form' [35].

Attending to the analytical focus on the whole, we approached our research question as a theoretical challenge, generating early conceptual ideas that would make sense of the initial data collection. Stimulated by dominant logic [30], we use different logical streams found in the data to describe the tension between vision and practice. These logical streams included operant conditioning, cognitive bias and cognitive simplification. Finally, conclusions were drawn based on constant discussions among authors in the flows of activities. The data collection activity and three types of activities form an interactive, cyclical process while keeping context in mind during analysis. In addition, the analysis also exhibited the move toward servitization based on remote diagnostics technology.

\section{Vision and practice at GlobalAlpha}

Although the history of providing services as a support function to GlobalAlpha's products dates back to 1985 , the firm came with vision to include services as a part of its main businesses in 2000s. In 2009 , the company came up with a scope to develop digital services on the basis of remote diagnostics technology in order to exploit maximum value for its existing vehicle manufacturing business. The situation was leading the firm toward servitization of its existing products. In this section, we present the findings from the empirical material regarding tensions between digital visions and product practices during digitalization.

\subsection{Servitization and technology at GlobalAlpha}

Through the analysis of the empirical material, we found that GlobalAlpha mainly holds the vision of adding digital service share to their existing business. At present, the company earns a major part of its revenue from selling manufactured physical goods. The advent of embedded remote diagnostics technology provides information about health status of vehicles. This information can be used to develop digital services, package them and sell to the customers. This broadens the scope of the company to conduct business in service the sector as well as selling manufacturing goods. Such a vision has been narrated and described by many top managers from different business areas, project managers, service planners and developers, and business managers.

The vision of incorporating services into their existing product has been described in the project and other company documents. This vision was also expressed in initial project meetings and in the interviews we conducted. We found more than 15 observations of the firm's vision related to the move towards a service oriented business based on digital technology. For example, the manager from Alpha 2 has expressed the vision in the following way:

"We are trying to add services with the vehicles. Traditionally, we sold vehicles and that was it. Now we are trying to be more customer-centric through adding services. Because we know that we will not be able to survive in the future by selling only the vehicles. So, we need to do something regarding the services."

Remote diagnostics technology plays a crucial role to achieve the vision. It has been emphasized in the following manner:

"Remote diagnostic may be used for uptime services of the commercial vehicle and to create commercial offerings in the future."

At another point a manager at Alpha 1 described rather wider scope of the technology as:

"RDS is not just about monitoring the status of the engine. Several services can be developed based on the remote diagnostics technology and many services can be included later on with the existing services. For example, I can see that driver behavior can also be examined through this technology to 
check how smoothly or roughly the driver drives the bus."

While the importance of technology as the basis of developing and providing services was mentioned in these words:

"We want the telematics solution to remotely read off machine hours which is one of the most important parameters to control the servicing of machines".

The statement reflects the importance of digital technology i.e. telematics solution to which remote diagnostics is an integral part in providing digital services. Without this technology, services cannot be generated and provided to the customers.

On the other hand, when the company and its subsidiaries were attempting to increase its share in service business, they created a strategy almost a decade ago with the focus on marketing information (an approach similar to product oriented business). The main part of the strategy was to implement remote diagnostics technology like any other IT strategy, but it did not work. Hence, servitization based on digital technology require new strategies different from general IT strategies. This has been narrated by one of the managers at Alpha 1 in such words:

"We created a new marketing package 10 years ago thinking that it will solve our problems. Still the result is same, $10 \%$ penetration. So, it is confirmed that only marketing information is not enough to get the service working and have a success story.

After establishing the fact that GlobalAlpha in general, has a vision to move towards services, the next challenge was hot to implement the vision and make it a practice. However, this stage reveals the contradictions between the visions and the practices that lead to tensions.

\subsection{Digital visions, product practices and tensions at GlobalAlpha}

The findings from our study illustrate that GlobalAlpha has a vision closer to digital service focus. The remote diagnostics technology offer opportunities to develop digital services. The firm aims to design, develop, and deliver these digital services like other service-oriented business. The findings regarding vision at the firm contemplate number of reflections. First, the firm visions to expand its traditional product focus and move towards service oriented business. Second, the firm recognizes the importance of considering the customer as center of focus. Third, the firm has a vision about collaborating with customers in order to develop high quality digital services based on remote diagnostics technology. So, they have the vision that new businesses will include services as a part of their main business and involving different stakeholders. This is also expressed in their service design vision how to work with co-creation and customer involvement and it is also mentioned in other project and company documents. These observations indicate that the firm has a good sense when it comes to vision their expanding business. However, in general, we can say that it is not what the firm has become, that is what the firm has as a vision.

On the other hand, the practical approach of GlobalAlpha to develop and deliver digital services is pretty much based on its thinking with product focus and is contradictory to their vision. In the following sections, we will describe some of these contradictions between the visions and the practices during digitalization that leads to tensions.

\section{Tensions related to Technology Design and Development \\ Digitalization of the technology opts for a more} open innovation environment. However, the technology development is hindering the firm to open-up the platform (as an open tool to develop parts of technology such as for software development) for other business firms. An instance of such practices has been expressed as:

"No, the algorithm should be kept under full control. In the inside part, no one else can interfere”.

The empirical material reveals that the firm is taking technical design decisions without considering the impacts on the business level. The findings also reflect that people involved in developing remote diagnostics technology stick to their old thinking of considering it to support the vehicles. Other indications during technology development regarding customer concerns reflect the similar attitudes. An example of such an attitude is when a manager neglects the role of the customer in development. In one case, the firm did not consider the customer's scenarios for technology development because it does not fit their ideas of having total control through patents. Another important observation in the study illustrates that top management still position itself as a part of technology development for products rather than for digital services.

Tensions related to adaptation of digital technology as a part of work practice

Empirical material such as company documents and observations revealed that the company and its subsidiaries want to provide standardized digital services with quality. This requires the firm to adapt to changes at the workplace. The remote diagnostics technology is in place to support remote diagnostics 
services activities. However, the employees or responsible persons are ignoring the importance of using remote diagnostics at work practices. They are still treating digital services as an additional function to support their product rather than taking them as a prioritized work practice. This was highlighted by a maintenance and service manager as:

"Remote services manager and foreman were not so futuristic with respect to services and operate their operations in old fashion".

Remote service managers are persons or roles using remote diagnostics technology to identify the faults in the vehicles from a remote location. They also use the remote diagnostics to collaborate with other departments involved in the e-maintenance service activities. However, their practices of using the technology as a support function are contradictory with the servitization vision of the company.

Tensions related to co-creation with customers during digitalization

When it comes to co-creation with customers where digital technology provides an opportunity to work with multiple stakeholders, GlobalAlpha shows contradictory practices to its vision. For example, GlobalAlpha has realized the importance of working closely with customers based on experiences from their practices in manufacturing environment. Databases about service records from customer sites are important sources of information. They are coupled with the real time signal from the vehicles to provide accurate and efficient information about the vehicle health status. Such information is the basis for developing and providing services to the customers. A manager at Alpha 2 provides the vision about collaboration with customers (one of the stakeholders) in such words

"If we are creative and work with the customers, services can be developed from the database that shows how our customers are using the vehicles. The potential for developing services in that area is very big."

But in practice, they still have unyielding attitude in collaborating with customers. This has been put by one of the business area mangers as:

"There are difficulties with rigid attitude to service development and need to be balanced. For example, an attitude not to talk to customers etc.

Such contradictions between vision and practice related to collaboration with customers, hinders the ultimate goal of innovating services based on digital technology. This further creates tensions between the company and customers who are expecting mutual benefit during the process.

\section{Tensions related to collaboration in digital networks}

Similar situations, as in case of collaboration with customers, arise when working on a broader perspective within the network. GlobalAlpha claims to be open when it comes to work with other stakeholders (such as transport authorities, dealers) in addition to customers. One of the managers expressed that the firm consider other stakeholders' concerns but in practice, such a vision is not brought into the scene that can be observed by the company itself. When one of the interviewees (repair and maintenance manager) was asked to reflect on participation of other stakeholders during technology development and value creation, he analyzed the situation in these words:

"I would not say that I am seeing any shift. Perhaps some new actors pop up. But that didn't happen.”

Another manager at Alpha 1 states similar practices as:

"We followed what we think is logical for us internally..........."

This internal thinking within GlobalAlpha to develop technology and related services is an example of typical practice within manufacturing firms. Other activities during the project also yielded similar conclusions. In some cases, crucial input from other stakeholders is missing. Such contradiction on network level leads to tensions or lack of interest from other stakeholders.

Tensions in developing business model based on digital technology

Although GlobalAlpha provided the vision of having a business model that suits product-service business, their current business model does not reflect that standpoint completely. For example, a business area representative at Alpha 1 states the vision regarding business as:

“....... today we are not into value based selling. But I think in order to reach 50\% soft income; we need to move towards that”.

The above statement shows not only the company's concerns about increasing share in business but also that they are having most of their business from selling manufactured goods. Terms like value based selling and soft income are used for selling services and generating revenue based on remote diagnostics technology.

In practice the business is more or less like traditional manufacturing business and regard services as an additional feature to their product. Even the technology that forms the basis of services 
is sold in similar way. This has been echoed by one of the managers as:

"Now-a-days, we have started to sell attachments as soft products today like working tools you put on a machine, but that is also parts selling mentality it is not service sales mentality."

Another manager at Alpha 3 explicitly mentioned that their current business model is based on selling manufacturing products and lacks the technology based service business model. He clearly pointed out the contradiction between practice and vision as:

"Today the company is very much tangible product oriented but now we want to focus on providing services to the customers. We still don't have a business model for providing knowledge based services such as remote diagnostics services."

He further added that

"The current business model is basically for the tangible products."

The main concern that arise here is related to traditional practice of selling technology like physical products (based on their practices i.e. exploitative) rather than as a distinct product (i.e. based on nature of remote diagnostics technology which is exploratory). This results in building a perception about the technology as a low margin business.

The findings, in general, illustrate that firm's implementation is counterproductive to its visions and with that it is difficult to accomplish its goals. These contradictory practices to the visions exit because the firm is locked-in to its product thinking. For example, selling parts rather than value, design and development of technology by locking-in of technology, co-creating with customers, operation of providing services such as maintenance services, the way of doing business is still done in product oriented style. This implies that these practices are serving as a paradox to the firm's vision. The overall vision of the firm is to expand with service oriented business, but in practice the firm is not keeping pace with the development of digital technology and hence resulting in tensions.

\section{Discussion}

In order to answer our question: What are the tensions for incumbent manufacturing firms when expanding their business with digital services? we studied the tensions during digitalization at GlobalAlpha. In the previous section, we outlined the tensions related to design and development of digital technology, technology adoption at workplace, collaboration enabled by digital technology and business models for digital technology. On the basis of these findings, we elaborate our interpretations and discuss these tensions from a dominant logic perspective.

Prahalad and Bettis [30] suggest that the way top managers deal with the increasing diversity of strategic decisions caused by acquisitions or structural changes, depends on their cognitive orientation. The logic, in general, consists of the mental maps developed through experience in the core i.e. product dominant logic in this study. In the following we discuss how our findings relate to different streams such as operating conditioning; cognitive simplification and cognitive bias to explain contradiction between vision and practice in incumbent manufacturing firms.

Cognitive simplifications is described as (i) conventional beliefs or wisdom); and (ii) the pattern recognition process - "what worked before" . This cognitive simplification is reflected in the tensions relating to the design and development of technology. It is also observed in adoption of digital technology in work practice, and collaboration with customers as well as with other stakeholders. For example, the limited purpose use of the technology (i.e. the use of technology for add-on function to product rather than for digital services) makes the adoption of technology difficult at workplace. Similarly, for technology design and development, GlobalAlpha is strict to have full control over technology without giving any freedom regarding development to other stakeholders.

Operant conditioning refers to doing the "right things" with respect to the business logic. This is done by performing the tasks that are critical for success and this leads to focus on behaviors that lead to economic success. At GlobalAlpha, the right business logic is to create and propose value in a closed environment. Examples of these include patents and by lock-in technology. Another critical task for success is to use existing product oriented business models in the absence of appropriate business model for digital services. This leads to low profit out of technology. GlobalAlpha has been successful in the product market by selling vehicles and parts as a complete package along with different service contracts as add-on. This strategy makes the firm one of the successful players in the vehicle sales market. The firm's management still follows the same practice as a successful strategy for its business regarding digital services.

Operating conditioning is achieved by acquiring a repertoire of tools and process from product oriented logic. For example, during collaboration the firm exhibits the behavior to tap knowledge from customers' technological system rather than sharing knowledge with them. This behavior results in 
transaction based relationship rather than sustainable relationship providing mutual benefit, according to the vision.

Cognitive Bias describes to how people in making decisions make systematic error. The cognitive bias is observed in technology design and development where people in charge are not involving (potential) customers during development. In this way, the firm is making systematic error of working in a closed environment. A similar trend of making systematic errors is observable in developing business models for digital technology i.e. to sell digital technology parts like physical products. For example, to offer vehicle parts and digital services as add on products rather than distinguished offers is part of their conscious in making decisions. This may result in low profit or even loss for the business, but more importantly missed opportunities for business innovation. That goes against their vision of cocreation with customers and reflects the firm's cognitive bias with the aim to provide digital services.

Hence, the current practices at this leading manufacturing company contradict with its visions which lead to tensions during digitization.

\section{Conclusion}

We set out to increase our understanding of tensions from a dominant logic perspective. From our study, we conclude that incumbent firms undergoing transition in the age of digital innovation experience tensions related to (i) digital technology design and development; (ii) collaboration with customers; (iii) network; (iv) workplace routines; and (v) business model development. These tensions are embedded in 'dominant designs' and mindsets regarding product, market and organization, in systems of exploitation. These tensions are related to exploration and exploitation and their understanding will inform firms about paradoxical situation that hinders innovation process. We conclude that a synergy is necessary between exploration and exploitation of digital technology to make innovation successful. We argue that tensions are created during organizational adaptation of technology at workplace, control over technology design and development, and working in closed environment.

As discussed in the introduction, the study of understanding tensions has been recognized as an emergent phenomenon of study [11, 36]. We concur with other findings that locating paradox requires taking into consideration the diversity of interpretations possible in order to detail contradictions in absurdity and weirdness or in brightness and curiosity [37]. While other scholars have considered tensions with respect to culture [19], institutions using institutional and regime theories [38], and resource-based view [39], we argue that digitalization bring specific tensions related to digital technology. Such tensions may be nested across levels of analysis [2], dominant logic address these by considering individual behaviors, by considering cognitive maps, and the associated problem-solving behavior. It sometimes becomes the only way to do things and it builds up over long time as the only way to do it (e.g. developing new product). It is also interesting to note that that some parts of the situation are given by structures and some parts are given by social constructions. So, dominant logic is a structure and example of it include patents, project models how to do projects etc. and then there also exists product focused culture.

Our study provides important insights to understand the role of tensions in incumbent manufacturing firms as inhibitors to change when firms want expand their business based on digital technology. Our study is conducted within the vehicle industry focusing on incumbent manufacturing firms and thus limiting our results for generalization to other industries. However, it provides useful observations about tensions that emerge due to contradiction in vision and practice. A further comparative study with other industries may help to elaborate on the theory.

\section{References}

[1] March, J.G., "Exploration and Exploitation in Organizational Learning", Organization Science, 2(1), 1991, pp. 71-87.

[2] Andriopoulos, C., and Lewis, M.W., "ExploitationExploration Tensions and Organizational Ambidexterity: Managing Paradoxes of Innovation", Organization Science, 20(4), 2009, pp. 696-717.

[3] Davies, A., "Moving Base into High-Value Integrated Solutions: A Value Stream Approach", Industrial and Corporate Change, 13(5), 2004, pp. 727-756.

[4] Baines, T.S., Lightfoot, H.W., Benedettini, O., and Kay, J.M., "The Servitization of Manufacturing: A Review of Literature and Reflection on Future Challenges", Journal of Manufacturing Technology Management, 20(5), 2009, pp. 547-567.

[5] Henderson, R.M., and Clark, K.B., "Architectural Innovation: The Reconfiguration of Existing Product Technologies and the Failure of Established Firms", Administrative Science Quarterly, 1990, pp. 9-30.

[6] Gebauer, H., Krempl, R., Fleisch, E., and Friedli, T., "Innovation of Product-Related Services", Managing Service Quality, 18(4), 2008, pp. 387-404.

[7] Barrett, M., and Prabhu, J., "Service Innovation in the Digital Age", Call for Papers-MIS Quarterly Special Issue 
on Service Innovation in the Digital Age (Available at: http://www. misq. org/skin/frontend/default/misq/pdf/CurrentCalls/SI_Service Innovation. pdf), 2010,

[8] Van Dijk, S., Berends, H., Jelinek, M., Romme, A.G.L., and Weggeman, M., "Micro-Institutional Affordances and Strategies of Radical Innovation", Organization Studies, 32(11), 2011, pp. 1485-1513.

[9] Anderson, P., and Tushman, M.L., "Technological Discontinuities and Dominant Designs: A Cyclical Model of Technological Change", Administrative Science Quarterly, 1990, pp. 604-633.

[10] Benner, M.J., "Securities Analysts and Incumbent Response to Radical Technological Change: Evidence from Digital Photography and Internet Telephony", Organization Science, 21(1), 2010, pp. 42-62.

[11] Smith, W.K., and Lewis, M.W., "Toward a Theory of Paradox: A Dynamic Equilibrium Model of Organizing", Academy of Management Review, 36(2), 2011, pp. 381403.

[12] Hylving, L., Henfridsson, O., and Selander, L., "Digital Technology in Product Development: The Moderating Role of Dominant Design", JITTA: Journal of Information Technology Theory \& Application, 13(2), 2012,

[13] Tilson, D., Lyytinen, K., and Sørensen, C., "Research Commentary-Digital Infrastructures: The Missing Is Research Agenda", Information Systems Research, 21(4), 2010, pp. 748-759.

[14] Lusch, R.F., Vargo, S.L., and Wessels, G., "Toward a Conceptual Foundation for Service Science: Contributions from Service-Dominant Logic", IBM Systems Journal, 47(1), 2008, pp. 5-14.

[15] Yoo, Y., Henfridsson, O., and Lyytinen, K., "Research Commentary - the New Organizing Logic of Digital Innovation: An Agenda for Information Systems Research", Information Systems Research, 21(4), 2010, pp. 724-735.

[16] Andriopoulos, C., and Lewis, M.W., "Managing Innovation Paradoxes: Ambidexterity Lessons from Leading Product Design Companies", Long Range Planning, 43(1), 2010, pp. 104-122.

[17] Raisch, S., and Birkinshaw, J., "Organizational Ambidexterity: Antecedents, Outcomes, and Moderators", Journal of Management, 34(3), 2008, pp. 375-409.

[18] Cameron, K.S., and Quinn, R.E., "Organizational Paradox and Transformation", 1988,

[19] Johnston, S., and Selsky, J.W., "Duality and Paradox: Trust and Duplicity in Japanese Business Practice", Organization Studies, 27(2), 2006, pp. 183-205.

[20] Diefenbach, T., and Sillince, J.A., "Formal and Informal Hierarchy in Different Types of Organization", Organization Studies, 32(11), 2011, pp. 1515-1537.

[21] Garud, R., Gehman, J., and Kumaraswamy, A., "Complexity Arrangements for Sustained Innovation: Lessons from 3m Corporation", Organization Studies, 32(6), 2011, pp. 737-767.

[22] Sundaramurthy, C., and Lewis, M., "Control and Collaboration: Paradoxes of Governance", Academy of Management Review, 28(3), 2003, pp. 397-415.
[23] Adler, P.S., Goldoftas, B., and Levine, D.I., "Flexibility Versus Efficiency? A Case Study of Model Changeovers in the Toyota Production System", Organization Science, 10(1), 1999, pp. 43-68.

[24] Smith, W.K., and Tushman, M.L., "Managing Strategic Contradictions: A Top Management Model for Managing Innovation Streams", Organization Science, 16(5), 2005, pp. 522-536.

[25] Tilson, D., Sorensen, C., and Lyytinen, K., "Change and Control Paradoxes in Mobile Infrastructure Innovation: The Android and Ios Mobile Operating Systems Cases", in (Editor, 'ed.'^'eds.'): Book Change and Control Paradoxes in Mobile Infrastructure Innovation: The Android and Ios Mobile Operating Systems Cases, IEEE, 2012, pp. 13241333.

[26] Lusch, R.F., and Vargo, S.L., "Service-Dominant Logic: Reactions, Reflections and Refinements", Marketing theory, 6(3), 2006, pp. 281-288.

[27] Vargo, S.L., and Lusch, R.F., "From Goods to Service (S): Divergences and Convergences of Logics", Industrial Marketing Management, 37(3), 2008, pp. 254-259.

[28] Gebauer, H., Fleisch, E., and Friedli, T., "Overcoming the Service Paradox in Manufacturing Companies", European Management Journal, 23(1), 2005, pp. 14-26.

[29] Gebauer, H., and Friedli, T., "Behavioral Implications of the Transition Process from Products to Services", Journal of Business \& Industrial Marketing, 20(2), 2005, pp. 70-78.

[30] Prahalad, C.K., and Bettis, R.A., "The Dominant Logic: A New Linkage between Diversity and Performance", Strategic Management Journal, 7(6), 1986, pp. 485-501.

[31] Bettis, R.A., and Prahalad, C.K., "The Dominant Logic: Retrospective and Extension", Strategic Management Journal, 16(1), 1995, pp. 5-14.

[32] Miles, M.B., and Huberman, A.M., Qualitataive Data Analysis: An Expanded Sourcebook, Sage Publications, 2nd edn, Thousand Oaks, CA USA, 1994.

[33] Myers, M.D., and Newman, M., "The Qualitative Interview in Is Research: Examining the Craft", Information and Organization, 17(1), 2007, pp. 2-26.

[34] Schultze, U., and Avital, M., "Designing Interviews to Generate Rich Data for Information Systems Research", Information and Organization, 21(1), 2011, pp. 1-16.

[35] Klein, H., and Myers, M., "A Set of Principles for Conducting and Evaluating Interpretive Field Studies in Information Systems", MIS Quarterly, 23(1), 1999, pp. 6794.

[36] Lewis, M.W., "Exploring Paradox: Toward a More Comprehensive Guide", Academy of Management Review, 2000, pp. 760-776.

[37] Teunissen, J., "Paradoxes in Social Science and Research", Contradictions in context, 17(1996, pp. 38.

[38] Wijen, F., and Ansari, S., "Overcoming Inaction through Collective Institutional Entrepreneurship: Insights from Regime Theory", Organization Studies, 28(7), 2007, pp. 1079-1100.

[39] Lado, A.A., Boyd, N.G., Wright, P., and Kroll, M., "Paradox and Theorizing within the Resource-Based View", Academy of Management Review, 31(1), 2006, pp. $115-131$. 